\title{
More with less: the almost ideal pension systems (AIPSs)
}

\section{Gustavo De Santis*}

\section{Abstract}

After exploring the rationale of pension systems, I outline the essential characteristics of 'almost ideal pension systems' (AIPSs), an improved version of the pay-as-you-go (PAYG) model. Depending on the policy choices, to be expressed in relative terms with parameters that range between zero and one, several-and possibly very different-forms of AIPSs can take shape: e.g. with high or low pension benefits, or with early or late retirement. (Almost) independent of the version chosen, AIPSs compare favourably in theory and in simulations to all other PAYG pension systems: for example, AIPSs are found to be superior in terms of their ability to ensure a balanced budget, intergenerational equity, resilience in the face of virtually all possible demographic and economic changes, and constancy at the preferred level for the relative economic well-being of the three basic age groups (young people, adults, and seniors). In addition, AIPSs are able to reduce, and even partly redress, the normally perverse redistributive effects that derive from heterogeneity in survival rates between subpopulation groups.

\section{Introduction}

Some time ago (De Santis 2003, 2011, 2012), ${ }^{1}$ I proposed a new family of pay-asyou-go (PAYG) pension systems, which I called 'almost ideal pension systems', or AIPSs. AIPSs were designed to serve both as a theoretical standard of reference against which to assess the performance of all other systems, and as a practical solution to the pension problems of the developed countries, especially in Europe, where mature, but usually unbalanced, PAYG pension systems already operate.

\footnotetext{
* Gustavo De Santis, DiSIA - Department of Statistics, Informatics, Application, Viale Morgagni, 59, 50134 Firenze, Italy

Email: gustavo.desantis@unifi.it
}

1 Sections 1 to 4 of this paper overlap with my previous work. The rest of the paper is new. 
There are an infinite number of possible versions of AIPSs with a common rationale but with very different shapes, depending on the policy choices (see below). In this paper, I do not discuss the 'best' possible form of AIPSs, or offer practical advice on how to transition from an existing pension arrangement to an AIPS. Instead, my goal is to illustrate the very general characteristics of the AIPSs subset.

The name itself calls for some clarification. Even if, as we will see shortly, this type of arrangement proves superior to all of its PAYG alternatives (defined benefit (DB), defined contribution (DC), notional defined contribution (NDC), and risk sharing (RS)), there are several reasons why many observers consider AIPSs to be less than ideal. First there are trade-offs which cannot be ignored. For example, more generous pensions benefits must somehow be financed, either through higher contributions or later retirement (or both). Second, AIPSs allow for transfers of money between two or three population subgroups only: i.e. from people of working ages to seniors, and, if so desired, children. Meanwhile, a large share of the transfers which are standard features of the modern welfare state are not accounted for (e.g. protection against unemployment and poverty). Thus, AIPSs are not a panacea for all social problems, and need to be complemented by other welfare institutions. Finally, every element of AIPSs is defined in relative terms, while the absolute levels vary over time. For example, the retirement age moves in line with the changing average length of life, ${ }^{2}$ and the average amount of the pension benefit is not defined in euros, but as a fraction of the average earnings of adults in a specific period. Moreover, the payroll contribution rate oscillates over time around a predefined average. I have two responses to these kinds of objections. First, the future is unpredictable, and if some subgroups are protected from uncertainty, others will have to bear more than their 'fair' share of it. Second, working in strictly relative terms is the only way to make tenable promises which can be kept forever in every possible economic and demographic scenario, without the need to predict the future or to ever adjust the system.

AIPSs are an infinite subset of possible pension systems; the actual form they take depends on the policy choices (parameters ranging between zero and one). In this paper, I set out to prove that all of these versions share a number of desirable properties, including automatic adjustment to all demographic and economic shocks. The discussion is deliberately kept at a very high level of generality, and the examples which are occasionally provided are just that: examples. If AIPS were ever to be applied in practice, however, two more steps would be needed: 1) the preferred set of policy parameters would have to be chosen (and, possibly, protected from ill-considered changes over time, by, for example, requiring that qualified parliamentary majorities approve any revisions), and 2) a plan for transitioning from the current situation to the selected form of AIPS would have to formulated. Both

2 AIPSs can also work with fixed threshold ages, but this variant is not discussed here. 
steps present several theoretical and practical challenges ${ }^{3}$ which cannot be discussed here. In all of my examples, I will simply assume that a specific, somehow optimal form of AIPS is and has always been in existence.

After providing a general, but very schematic, overview of the rationale of pension systems (Section 2), and of AIPSs in particular (Sections 3 to 6), I run a simulation to support my claim that AIPSs are better than other PAYG pension arrangements (Section 7). I conclude with a discussion of the issue of heterogeneity and intra-generational equity (Section 8).

\section{A selected presentation of the aims and risks of pensions systems}

Very broadly, pension systems do two main things: they "provide income security to retirees, [and] they may also aim at redistribution across population groups, such as lifting the low-income elderly out of poverty" (Kohli and Arza 2011, p. 251; my emphasis). As pension systems are complex and expensive, several key issues tend to arise in discussions of these systems, most of which have been mentioned by (Kohli and Arza 2011) themselves. In this paper, however, I will focus on two issues in particular: viability and risk distribution.

Viability is a notion that parallels that of 'sustainable development' (UN 1997): a pension system must be designed so that it can be maintained indefinitely in its present form without significantly depleting or degrading resources (e.g. reserve capital) and without adversely affecting future generations. Of course, the rules of the pension system can be changed over time if social preferences vary, but if change proves to be unavoidable (e.g. because the system is collapsing), then some groups will have taken more than their share, while other groups-typically the younger generations - are left to pay the bill.

Viability introduces two main constraints. The first constraint is the need to balance the budget: i.e. inflows must match outflows. This, however, rarely happens in practice. ${ }^{4}$ The second constraint is one which economists tend to emphasize: namely, that pension systems should not (even unintentionally) induce negative economic side effects. One such effect is the potential impairment of current or future production, which occurs in two main ways: labour market participation may be discouraged by high taxes or early retirement schemes (Gruber and Wise 1999; Sánchez-Romero et al. 2013; OECD 2013), and savings may be depressed (BörschSupan 2008).

3 Complex utility functions would have to be maximized, taking into account the possible adaptive reactions of individuals and institutions. Past promises would also have to be taken into account.

4 A (limited) structural imbalance could be theoretically justified, to the extent that the pension system is considered a public good (like the legal system or national defence) which is partly financed with taxes. This variant, not discussed here, would not affect the working of AIPSs. 
It is occasionally argued that funding a pension system is better than relying on PAYG. But this assertion is both unwarranted (Orszag and Stiglitz 2001; Barr 2002) and irrelevant, because existing PAYG pension systems cannot be (easily) dismantled. Thus, the only viable option is to reform these systems. In these reform efforts, (actuarial) equity ${ }^{5}$-i.e. a close correspondence between the amounts people pay into the system in their adult years and the amounts they receive in retirementis deemed essential to induce participation in both the official labour market and the pension system. Unfortunately, equity is difficult to achieve, both given the budget constraints (that is, how can future pension resources be matched exactly with the actuarially fair expectations of future retirees?) and the need to redistribute benefits to favour the poor. Thus, it appears that some sort of compromise between these conflicting demands is needed.

As for the risk issue — which I am discussing here only very schematically - the main question is who gains and who loses if projections prove to be inaccurate. For example, economic growth, employment rates, inflation, or population ageing may not develop as expected. Pension schemes rarely tackle the issue of risk explicitly, but implicitly and in practice they always provide an answer. For instance, the defined contribution system (in which the payroll contribution rate is predefined) protects the employed because workers know in advance what fraction of their salary they will forego in order to make pension contributions, but leaves pensioners exposed to a substantial degree of income variation. Attempts to protect both age groups (adults and seniors) are not easily reconciled with the need to balance the budget. For example, the now popular notional defined contribution (NDC) system is designed to predefine both payments and benefits. In practice, however, this translates into either budget imbalances or the application of 'adjustment factors' (forcing pension benefits to correspond to the available resources), which reintroduces exposure to certain categories of risk. It therefore appears that 'risk sharing' between population subgroups (Musgrave 1981; Gonnot et al. 1995) is the best option - and AIPSs, as we will see, represent an improved version of this idea.

Two more issues may be considered. This first is fertility. It is already low in developed countries, and pension systems may aggravate the problem by depriving children of their economic utility for their ageing parents. Thus, several scholars have suggested that pension benefits should be linked not only to individual contributions, but also to individual fertility (Demeny 1986, 1987; Cigno and Werding 2007).

The second is the risk of 'inverse redistribution', or distribution from the poor to the rich. As pension systems transfer resources from working-age adults to the elderly, they favour long-living population subgroups, including higher earners, who on average spend proportionally more years in retirement and receive more benefits

\footnotetext{
5 Interest in actuarial equity has recently increased, which explains the popularity of NDC (notional defined contribution) systems (Settergren and Mikula 2006; Kruse 2010; Knell 2013; Sánchez-Romero et al. 2013; OECD 2013).
} 
than they paid for through contributions (Belloni et al. 2013). This anti-egalitarian feature is normally more than counterbalanced by other mechanisms through which the rich are 'taxed' and forced to transfer a portion of their pension contributions to the poor. These mechanisms are, however, complicated, and can be difficult to control.

\section{The basics of AIPSs - almost ideal pension systems}

As was noted above, AIPSs (almost ideal pension systems) ${ }^{6}$ are not a single specific PAYG pension arrangement. They are an infinite subset of arrangements based on a system of relationships between three types of variables: policy, exogenous, and dependent.

Policy choices, which ideally would be considered very carefully and then once made maintained forever (or at least protected from ill-considered changes by, for example, requiring that qualified parliamentary majorities approve all revisions), are to be expressed in the form of parameters, ranging between zero and one on the following five relative variables:

i. The proportion of life to be spent in the (arbitrarily defined) conditions of young $\left(Y^{*}\right)$ and old (or senior, $S^{*}$ ). What remains is the proportion spent in adulthood $A^{*}=1-Y^{*}-S^{*}{ }^{7}$

ii. The relative standard of living the pension system must provide to the young through child benefits $(\chi)$, and, on average, to seniors through pension benefits ( $\pi$; both child benefits $B$ and pension benefits $P$ are relative to the average net adult labour income ${ }^{a} W$ ).

iii. The relative importance of actuarial equity $(Q)$ vs. redistribution $(1-Q)$ within the system.

\footnotetext{
6 In the following, I will keep the presentation at the simplest possible level, and I will assume that a) a unique AIPS covers the entire population, with budget equilibrium (revenues match outlays) and no side costs (e.g. management costs and interests); b) the current (cross-sectional, time-varying) life table constitutes a convenient standard of reference for the asymptotic age structure of the population; and c) the reference shares of young people, adults, and seniors are kept constant forever $\left(Y^{*}, A^{*}, S^{*}-\right.$ see below). All of these assumptions can be relaxed (not shown here). Wages may be gross $G$ if considered before the payment of the contributions $C$ to the pension system, or net W after this payment (eq. (3)). All of the economic variables are before income tax (not considered here).

7 Asterisks denote the variables (or parameters) of the reference population: $Y^{*}, A^{*}$, are $S^{*}$ are simply (constant) quantiles of the life years in the reference (here: stationary) population. The ratios (e.g. $S^{*} / A^{*}$ ) that derive from these proportions (eq. (1)) are called 'life course ratios' by Sanderson and Scherbov (2013, p. 677).
} 
The independent variables are assumed to vary unpredictably. ${ }^{8}$ Luckily, there is no need to forecast them. These variables may instead be observed in each year $t$ (and, when relevant, for each age $x$ ). The relevant variables are:

a. the 'reference' age structure (the age structure of the current stationary population $\left.{ }^{9}\right) L_{t, x}$,

b. the age structure of the current population $P_{t, x}$,

c. the employed $E_{t}$ and their gross wage $G_{t}$, and

d. for each 'senior' $s$ (anybody aged $\beta_{t}$ or over), the current value of his or her total (past) contributions to the pension system, or virtual capital, $K_{s, t}$, and the average of these virtual sums $K_{t}\left(=\sum_{s}{ }^{s} K_{t} / S\right)$.

The combination of the exogenous, time-varying variables (a-d) and the (ideally constant) policy parameters (i-iii) determines the dependent variables of the system as follows:

1. Threshold ages: The age structure of the reference (stationary) population provides the current total number of life years $T_{t, 0}=\Sigma_{x} L_{t, x}$. The (time-varying) threshold ages $\alpha_{t}$ and $\beta_{t}$ must be such that $Y^{*}\left(=T_{t, 0-\alpha} / T_{t, 0}\right)$ and $S^{*}\left(=T_{t, \beta+} / T_{t, 0}\right)$ are exactly at their target (policy) values (Figure 1).

2. Age groups: The (exogenous) age structure of the population and the threshold ages (shown in Figure 1) produce the current number of young, adults, and seniors in the population $\left(Y_{t}, A_{t}\right.$, and $S_{t}$; Figure 2$)$.

3. Contribution rate: Given the policy parameters $\chi$ and $\pi$ (relative levels of child and average pension benefits) and the population shares, two equilibrium contribution rates can be computed: the current rate $\left(c_{t}\right)$ and the reference rate $\left(c^{*}\right)$ :

$$
\begin{gathered}
c_{t}=\frac{S_{t} \pi+Y_{t} \chi}{A_{t}+S_{t} \pi+Y_{t} \chi} \\
c^{*}=\frac{S^{*} \pi+Y^{*} \chi}{A^{*}+S^{*} \pi+Y^{*} \chi}
\end{gathered}
$$

$c_{t}$ varies over time, together with the current proportions of young people, adults, and seniors in the population; but remains around an average (or asymptotic) value which is $c^{*}$ with no (or relatively little or only temporary) migration, and is very close to $c^{*}$ when migration is instead strong and persistent (see De Santis, 2011, and Figure 6, below).

\footnotetext{
8 Even mortality, the most regularly evolving demographic phenomenon in the past 60 years, has systematically defied the expectations of the experts (Oeppen and Vaupel 2002; Shkolnikov et al. 2011). In all cases, everything is by definition unpredictable in the long run, and AIPSs are designed to last forever.

9 Perhaps averaging over the most recent $n$ (e.g. three or five) life tables so as to smooth changes, or considering the alternatives (e.g. CAL, or 'lagged cohort life expectancy'; (Guillot and Kim 2011)). However, neither option is discussed here. In all cases, small errors in the choice of the reference populations are of scarce theoretical and practical relevance.
} 


\section{Figure 1:}

Four examples of reference age structures (with $\mathrm{e}_{0} \approx 60,70,80$, and 86, respectively) with their corresponding threshold ages when $Y^{*}=20 \%$ and $S^{*}=20 \%$ (illustrative policy choices)
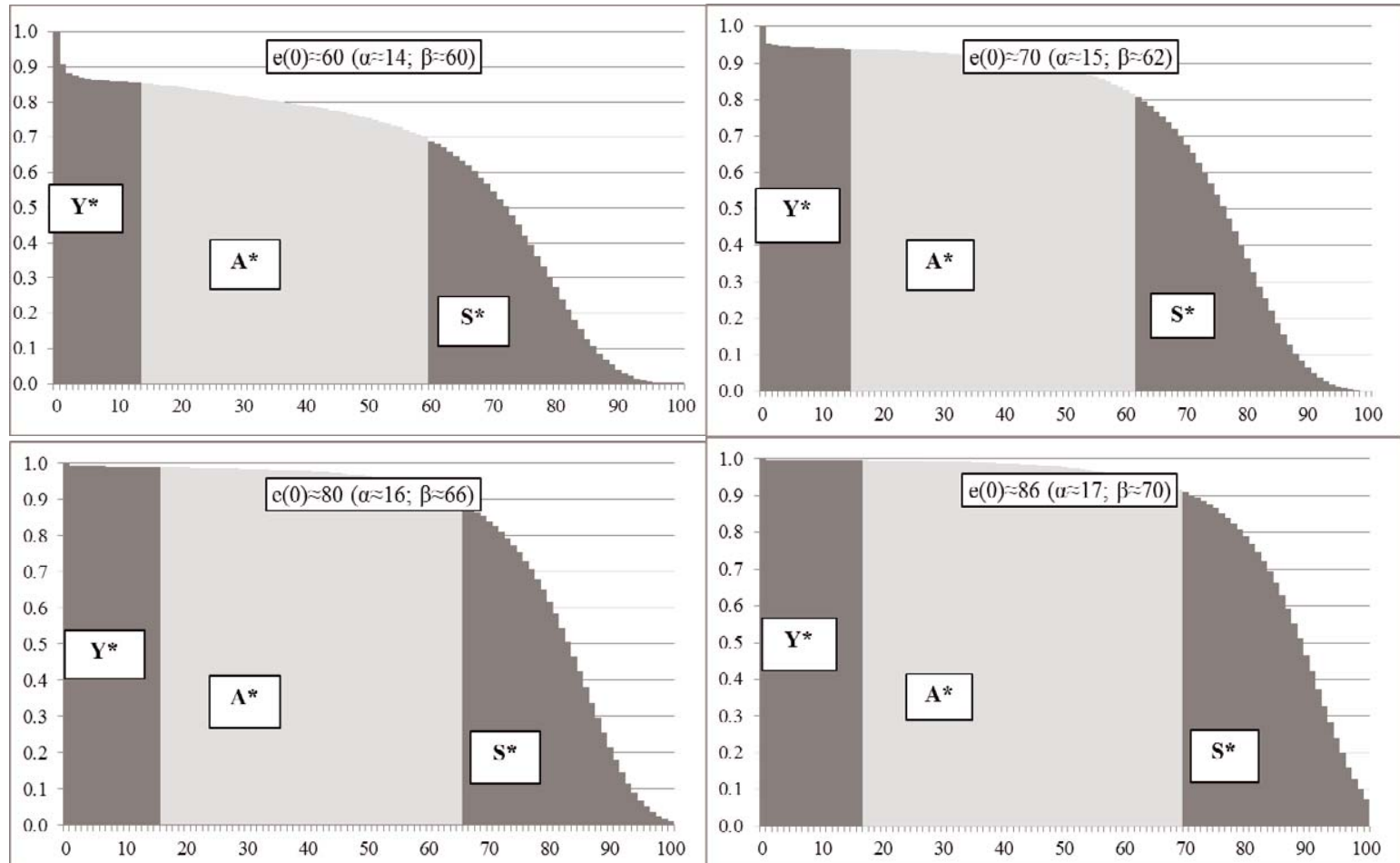

Source: HMD (period data for Italy 1946, 1957, 1989 and Japan 2009; women) and the author's calculations.

4. The net (average) wage of the employed $W_{t}$ is their gross wage $G_{t}$ minus their contributions $C_{t}\left(=G_{t} c_{t}\right)$ to the pension system

$$
W_{t}=G_{t}-C_{t}=G_{t}-G_{t} c_{t}=G_{t}\left(1-c_{t}\right)
$$

5. The net (average) wage of the adults ${ }^{a} W_{t}$ is

$$
{ }^{a} W_{t}=W_{t} \frac{E_{t}}{A_{t}}=W_{t} e_{t}
$$

where $e_{t}=E_{t} / A_{t}$ is the employment rate at time $t$, and ${ }^{a} W_{t}\left(=W_{t} e_{t}\right)$ is the total labour production per adult. ${ }^{a} W_{t}$ encompasses both (average) labour productivity $W_{t}$ (of the employed) and participation $e_{t}$-in short, all the essential information about the labour market.

6. Child benefits $B_{t}$ and the average pension benefit $P_{t}$ are pegged to this new variable ${ }^{a} W_{t}$ through the policy parameters $\chi$ (relative child benefit) and $\pi$ (relative pension benefit)

$$
\begin{aligned}
& B_{t}=\chi^{a} W_{t} \\
& P_{t}=\pi^{a} W_{t}
\end{aligned}
$$


7. While child benefits $B_{t}$ are the same for all children, individual pension benefits ${ }^{s} P_{t}$, may (and arguably should) be linked to past contributions. The relative importance of each senior's past contribution is ${ }^{s} K_{t} / K_{t}\left({ }^{s} K_{t}\right.$ and $K_{t}$ are, respectively, the individual and the average current values of the cumulated past contributions of the seniors to the pension system), and the weight of this component in the determination of individual pension benefits ${ }^{s} P_{t}$ is the policy parameter $Q(0 \leq Q \leq 1)$

$$
{ }^{s} P_{t}=\underbrace{Q \frac{{ }^{s} K_{t}}{K_{t}} P_{t}}_{\text {Bismarck }}+\underbrace{(1-Q) P_{t}}_{\text {Beveridge }}=P_{t}\left(1-Q+Q \frac{{ }^{s} K_{t}}{K_{t}}\right)
$$

Individual pension benefits have a 'Bismarckian' and a 'Beveridgean' element. The former element links current benefits $\left({ }^{s} P_{t}\right)$ to past contributions $\left({ }^{s} K_{t}\right)$, the importance of which is assessed in relative terms $\left({ }^{s} K_{t} / K_{t}\right)$ and weighs $Q$ [policy choice; $0 \leq Q \leq 1]$. The latter weighs $(1-Q)$ and is redistributive: i.e. it tends to give every senior the same (average) pension.

Equation (7) shows that the average $P$ of all pension benefits is precisely what the system needs to be in equilibrium, which rarely occurs in pension systems. ${ }^{10}$ Moreover, this approach forces policy makers to state explicitly the exact degree of actuarial equity $Q$ and redistribution $(1-Q)$ they want the system to have. ${ }^{11}$

\section{The rationale of AIPSs}

Even in this still very general form in which no policy decision has yet been taken, AIPSs display some advantages over most or all of the alternatives. First, this system minimizes the political risks associated with pensions which may arise when current generations appear to be taking advantage of future generations (Orszag and Stiglitz 2001; Barr 2002). This is because all of the policy decisions-i.e. the five parameters $Y^{*}, S^{*}, \pi, \chi$, and $Q$-are, by definition, general, explicit and (forever) viable.

Second, AIPSs have the explicit goal of keeping intergenerational transfers in line with current production, measured in terms of labour production per adult ${ }^{a} G_{t}$ (= 1 , the implicit economic numeraire of the system), and consistent with collective preferences regarding how much to transfer $(\pi$ and $\chi$ ), and to whom: generally, only

10 The Swedish pension system is an exception, but it solves the problem in a more complicated way. More importantly, it modifies only pension benefits without touching the contribution rate (Kruse 2010), which means that the burden of the adjustment falls entirely on the seniors. The same holds for the 'point system' that some countries use; e.g. Germany.

11 Equation (7) implicitly defines the minimum pension benefit, paid to those who never contributed to the system $\left({ }^{s} K=0\right):{ }^{\min } P=(1-Q) P$. Note that this minimum pension may be very low; even zero if $Q=1$. 


\section{Figure 2:}

Reference and current age structure in Italy, 2010 (where $\mathrm{e}_{0} \approx 81.6$ ) with their corresponding threshold ages when $Y^{*}=20 \%$ and $S^{*}=20 \%$ (illustrative policy choices)

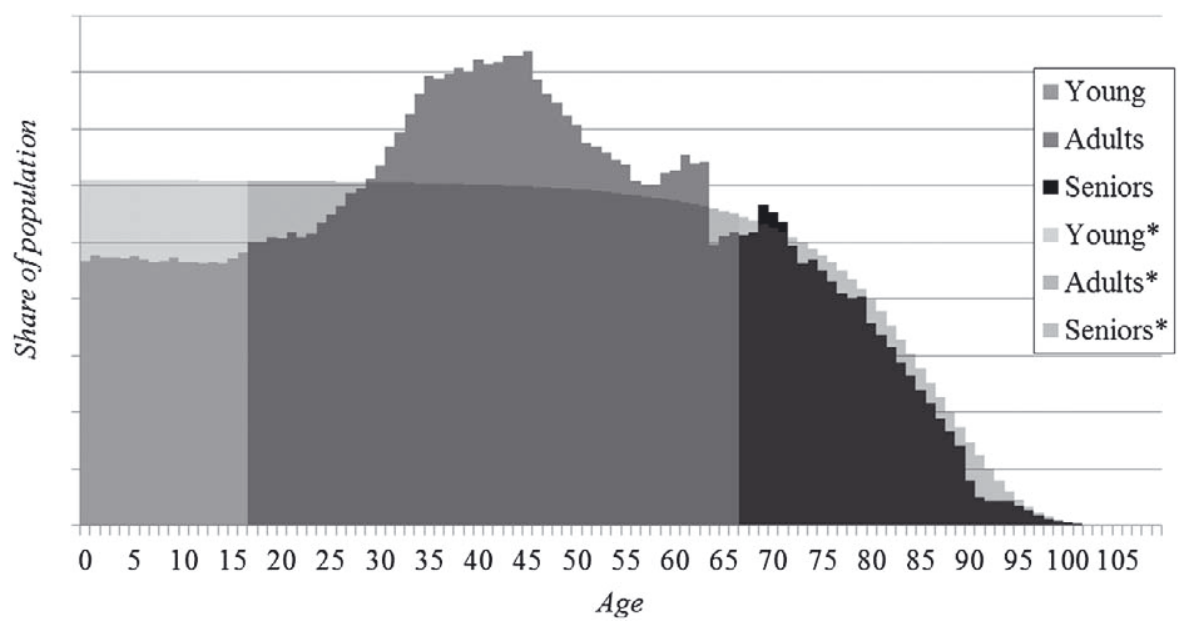

Note: Life table: average of men and women, years 2009-2010.

Source: Istat and the author's calculations.

to individuals who are conventionally considered too old (or too young) to work and earn a living. ${ }^{12}$

Declining mortality is the single most important cause of population ageing (Preston and Stokes 2012). But with constant 'life course ratios', longer life spans cease to be an issue: every extra year of life is automatically divided into the three shares $\left(Y^{*}, A^{*}\right.$, and $\left.S^{*}\right)$ which had been agreed upon at the start, and which preserve the reference contribution rate $c^{*}$ (eq. (2)) at its original, socially preferred level. $^{13}$

However, mortality and, to an even greater extent, migration and fertility affect the current age structure of the population. Low fertility, for instance, causes ageing, and when there are more seniors and fewer adults, the contribution rate increases (eq. (1)). This lowers the net wages of both the employed $\left(W_{t}\right)$ and the adults $\left({ }^{a} W_{t}\right)$,

12 But both children and seniors can, and are implicitly encouraged to, work in the market: in this case they earn both their wage and their pension (or child) benefit. Collectively, this results in higher employment $e=E / A$; higher adult labour income ${ }^{a} W$, and (with constant $\pi$ and $\chi$ ) higher transfer benefits. Child benefits can, in an AIPS, be used to counteract the fertility-depressing effect of pension systems (not discussed here).

13 Other versions of AIPS with fixed $\alpha$ or $\beta$, or both, are also possible (albeit worse), but are not discussed here. Just how reactive the threshold ages must be to variations in life expectancy can be inferred qualitatively from Figure 1. Note, however, that while the threshold ages serve exclusively to define who in the population is to be considered a young person, an adult, or a senior (and therefore is or is not entitled to an age-related benefit); they have no other implications: for instance, nobody is obliged to join or leave the labour market at any age. 
which through the constant (policy) parameters $\pi$ and $\chi$ spreads to pensions and child benefits. Thus, all are worse off, but the relative position of each group remains unaffected (see also the simulation of Section 7). A similar scenario may also occur when the age structure shifts because of changes in migration (De Santis 2011) or mortality.

On the economic front, an increase in production (e.g. because of higher labour productivity $W_{t}$, or employment $e=E / A$, or both) translates into higher values of ${ }^{a} W_{t}$, and with constant $\pi$ and $\chi$, into higher benefit transfers. In short, when the economy improves (or deteriorates), all of the three population groups are, on average, equally better (or worse) off.

\section{What if variables assumed to be exogenous are instead endogenous?}

A few key variables of the system may be endogenous, at least in part. For example, labour force participation, especially at older ages, depends very much on the characteristics of the pension system itself. Can AIPSs depress labour force participation?

There are two possible answers here. The simplest is that AIPSs are an infinite set of possible pensions arrangements, the nature of which depends entirely on the five policy choices (parameters) indicated above. A discussion of this issue is not appropriate here, as it is the responsibility of national parliaments and governments - preferably with the help of welfare and labour experts- to select the combination of parameters which 'maximizes utility', however it is defined. Take $Q$, for instance: the higher it is (up to one), the closer is the correspondence between past contributions and future pension benefits. In this case, what is taken from labour income is not a tax but forced saving, which is returned to the workers a few years later after they enter retirement. This arrangement would not be expected to discourage labour participation. On the other hand, a high value of $Q$ will leave a large number of seniors who made small (or no) contributions to the pension system while working with low (or no) pension benefits. Picking 'the best' $Q$ for each country is strictly a matter of social preferences (probably mediated by policy makers).

The second answer is that, excluding very extreme policy choices (e.g. $Q=0$ ), AIPSs tend to raise, not lower, the employment rate $e$ in two ways. First, no pension benefit is ever paid before age $\beta .{ }^{14}$ Second, pension benefits are also paid from age

14 Which apparently deprives the employed of the freedom to choose when to retire, and the fact that $\beta_{t}$ varies in time (increasing with $e_{0}$ ) makes things even worse. See (De Santis 2012) for a rebuttal. 
$\beta$ onwards to those with their own labour (or capital) income, ${ }^{15}$ which should give people a strong incentive to remain economically active.

AIPSs do not generally discourage saving, especially when compared to other pension systems. But again, the effects on saving depend on the policy choices. If transfers are very generous (high relative pension benefits $\pi$ and correspondingly high contribution rates $c^{*}$ and $c_{t}$ ), personal savings will likely be low, both because of budget constraints during working ages (when pension contributions are high), and because of a reduced incentive to save further as the level of forced saving is already high. But even in this case there will be some personal saving on the part of those who prefer (or fear that they may be forced) to retire early before reaching the standard (and moving) pensionable age $\beta_{t}$, and who want to secure a source of income between a fixed age (say, 60 years) and the official retirement age $\beta_{t+z}, z$ years from now. Once again, the question is what the best combination of parameters $(S *, \pi$, and $Q)$ is, not whether AIPSs are effective.

\section{AIPSs vs. NDC systems}

AIPSs have several features in common with notional defined contribution (NDC) systems. Both systems provide incentives to work in the legal labour market and to pay contributions because both are based on actuarial equity. Both AIPSs and NDC systems operate on the principle that the pension load must somehow be linked to the nation's current production levels (Barr 2002), though this link is looser in NDC systems than in AIPSs. In NDC systems, past contributions confer rights to a given pension amount, ${ }^{16}$ whereas in AIPSs past contributions confer rights to a given pension share of the current product.

AIPSs are more general (and therefore better) than the NDC system, which can in some senses be viewed as a version of AIPS: one with no redistribution $(Q=0)$, no automatic adjustment of threshold ages $(\alpha$ and $\beta$ ), no child transfers $(\chi=0)$, variability in the $\pi$ ratio (average pension benefit to average net adult wage), no consideration for the employment rate $e$, and an improper re-evaluation of past contributions.

In AIPSs, revenues (contributions) match outlays (pension and, possibly, child benefits) in every single year, while in NDC systems this is not guaranteed unless ex-post adjustment factors are introduced, as has been done in Sweden. With AIPSs all of the adjustments have exactly the same relative impact on all age groups thanks

\footnotetext{
15 The reason is that pension benefits are not a manifestation of benevolence: they are part of an intergenerational contract under which people agree to pay into the system in their working years with the expectation that they will receive the exact amount they were promised in their senior years. See also footnote 12 .

16 Although in practice this is mediated by the re-evaluation coefficients used to transform past contributions into their present, cumulated value.
} 
to the constant policy parameters $\chi$ and $\pi$, and no distinction is made between older seniors who retired long ago and newly retired seniors. ${ }^{17}$

Even those who favour a close correspondence between contributions and benefits normally leave some room for redistribution, which, incidentally, can compensate for the implicit inverse distribution (from the poor to the rich) inherent in all uncorrected pension systems because of the heterogeneity in survival rates (Section 8). With AIPSs, the precise degree of redistribution to the poor can be chosen and maintained forever.

\section{AIPSs at work in simulations with population homogeneity}

In the following I present several simulations which illustrate how AIPSs outperform alternative PAYG pension systems, both in a context of population homogeneity (this section) and in a context of heterogeneity (the next section).

\subsection{The demo-economic scenario}

Figure 3 summarizes the (very simple) demo-economic scenario of this section: life expectancy does not change $\left(e_{0}=84.4\right.$, panels $a$ and $\left.b\right)$ and migration is excluded. Fertility first declines, from TFR $\approx 2.1$ to 1.5 , and then recovers its initial (reproduction) level of TFR $\approx 2.1$ (panel $b$ ). The population declines by almost onethird in 100 years, and then stabilizes at the new, lower level (panel $c$ ). While the reference shares of young people, adults, and seniors $\left(Y^{*}, A^{*}\right.$ and $S^{*}$ - panels $d, e$, and $f$ ) never change (policy choice), the current shares $(Y, A, S)$ move in 'waves', and eventually return to their original (reference, asymptotic) level. The starting and the end points of the simulation are in equilibrium because I want to compare the performance of the various systems in troubled times (those in between), when everything else is under control. The scenarios extend for 300 years because I also want to investigate the intergenerational implications of the compared arrangements to find out whether there are unintended intergenerational gains or losses; and, if so, how high they are.

Mortality variations (improvements, notably) are excluded from this simulation not because they are unlikely to happen, but because their effect is obvious: either the threshold ages are adjusted upward in a proper and timely manner (preserving the chosen reference shares $Y^{*}, A^{*}$, and $S^{*}$ ), which brings us back to the scenario considered here; or they are not, which means that as the population gets older, contribution rates increase or pension benefits diminish (or both). However, the

17 In most pension systems, including in NDC systems, the relative position of the oldest seniors becomes progressively worse (vintage pensioners), because their initial pension benefits are not fully re-evaluated (based on prices and labour productivity). 
Figure 3:

Assumptions for a simulation on the operation of alternative PAYG pension systems

(a) Reference age structure

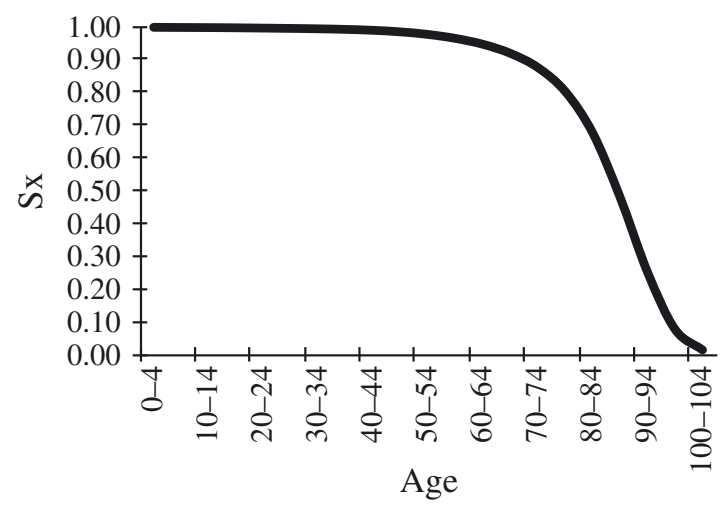

(c) Population: level and rate of increase

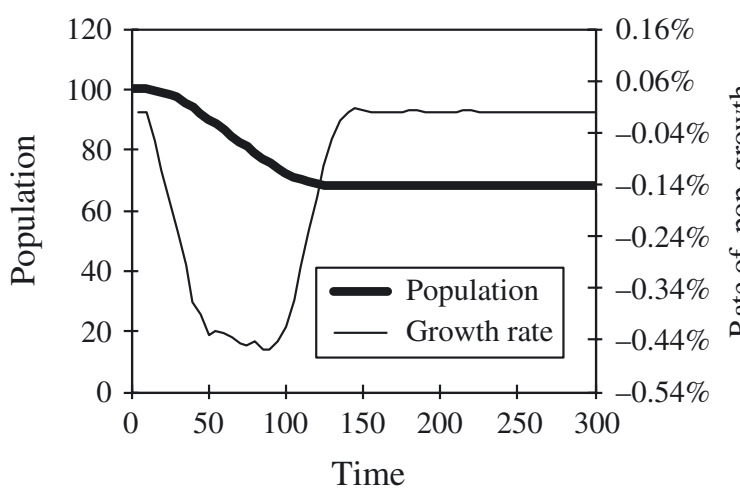

(e) Proportion adult

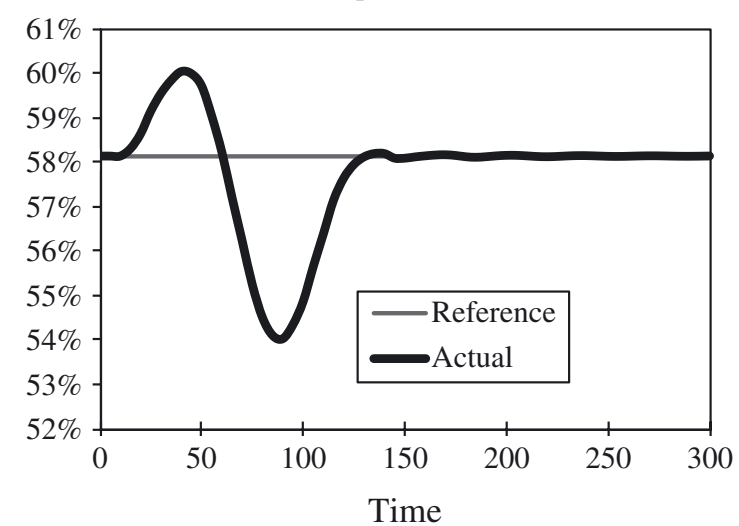

(b) Mortality and fertility

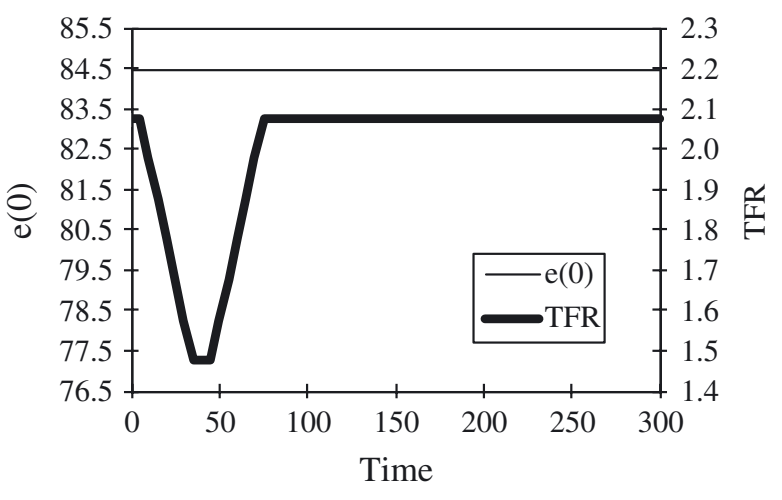

(d) Proportion young

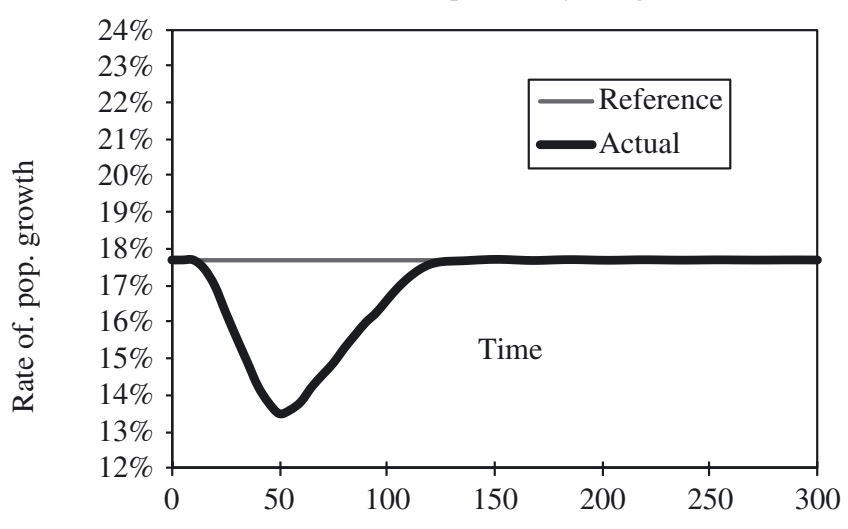

(f) Proportion old

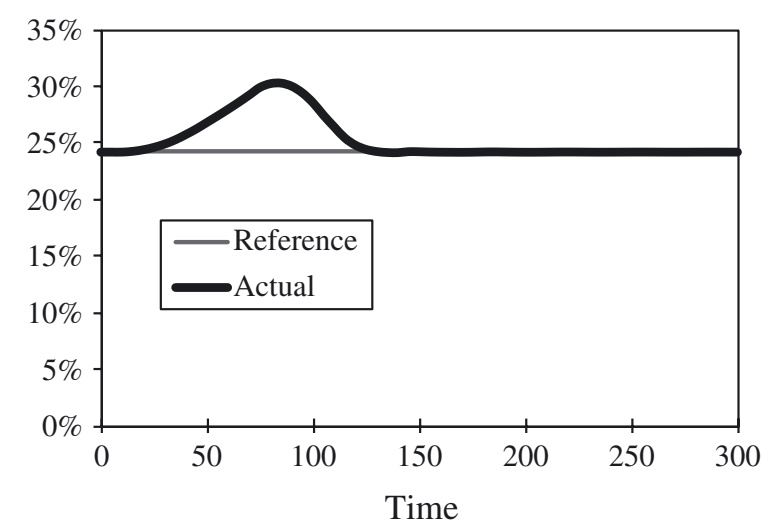

Source: Author's simulations. 
ranking of the various pension systems, along with their pros and cons, remains basically the same. ${ }^{18}$

The effects are similar for migration: the presence of immigrants makes things easier in the short run, because the old age ratio $S / A$ (seniors/adults) declines; but in the long run, as immigrants start to age, the age structure tends to return to its 'normal' state, which is generally similar to the reference age structure (De Santis 2011).

As for the economy, inflation is excluded here ${ }^{19}$. There is a slow increase in the employment rate $e=E / A$, from $70 \%$ to $76 \%$, counterbalanced by a decrease in labour productivity, from $G_{0}=1$ to $G_{300}=0.921$. The two variables evolve in such a way that $e G$ (gross total labour earning per adult: the key summary economic indicator in AIPSs) remains exactly the same for the entire period. My reason for making this very peculiar choice is my desire to highlight the fact that AIPSs are the only pension systems which automatically recognize that, in this case, the longrun standard of living of the community has not changed, despite the (mutually offsetting) changes in employment and labour productivity; consequently, there is no reason to change contributions and benefits.

\subsection{Four pension systems}

The simulation compares four pension systems. All are subject to budget constraints (contributions match benefits in every single year), and all have the same, purely illustrative, starting point: the contribution rate is $c_{0}\left(=c^{*}\right)=20 \%$, child benefits are excluded $(\chi=0)$, and the average pension benefit is $\pi_{t}=60 \%$ of the average net adult labour earning.

1. The defined contribution (DC) system stipulates that the contribution rate remain constant at $20 \%$.

2. The defined benefit (DB) system stipulates that pension benefits remain at their starting level (which happens to be $P_{0}=0.336$, where $G_{0}$, the average gross labour earning in year 0 , is one).

3. The risk sharing (RS) (Musgrave 1981; Gonnot et al. 1995) system stipulates that the ratio between the average pension and the average net labour earning of the employed $P_{t} / W_{t}$ remains constant (at $42 \%$ ).

\footnotetext{
18 In most cases, however, the superiority of AIPSs becomes even clearer (not shown here) because the threshold ages increase regularly with $e_{0}$ (not 'by jumps') and because all of the pension benefits (including those paid to very old pensioners) are properly adjusted every year, whereas most other arrangements protect the older pensioners and impose adjustments only on the younger ones.

19 This simplifies matters considerably and runs counter to my thesis. With AIPSs inflation is perfectly neutral by definition, thanks to the constant policy parameter $\pi$. In the other pension systems this is very rarely the case.
} 
4. The almost ideal pension system (AIPS) stipulates that the ratio between the average pension and the average labour earning of the adults $P_{t} /{ }^{a} W_{t}$ remain constant (at $\pi=60 \%$ ).

The NDC system is not explicitly considered in this scenario: its peculiarity lies in how it treats individual cases and not the average case discussed here. Moreover, in most of its practical applications (e.g. in Italy) it has no embedded budget equilibrium, and is therefore not comparable. If a balanced budget were to be introduced 'in the Swedish way'-that is, with a constant contribution rate but varying pension benefits - the NDC system would coincide, on average, with the DC system presented here. If a balanced budget were introduced by adjusting the contribution rate, the NDC system would not differ from the DB system. Finally, if the NDC system were introduced (with considerable complications) in a way that preserved a predefined ratio between pension benefits on the one hand and net labour earnings on the other (of the employed or of the adults), then it would coincide, at least in the aggregate, with the RS system or the AIPS.

\subsection{Three criteria for comparison}

My criterion of preference is constancy (or, as a second best, minimum variability) over time of a few key variables. These are, in decreasing order of importance:

1. the cross-sectional relative welfare $\pi_{t}$,

2. intergenerational equity $E^{g}$, and

3. the contribution rate $c_{t}$.

The cross-sectional relative welfare is simply the policy parameter $\pi$ of AIPS or the ratio between the average pension benefit and the average net adult labour earning. The basic idea is that the pension system should not lead to unplanned (and therefore, by assumption, socially undesired) changes in the relative standards of living of the three age groups relevant for the system: young people, adults, and seniors. $^{20}$

All of the generations should ideally get back as pensioners the contributions they paid in while working. This is an explicit goal of funded systems, but the issue also matters in PAYG pension systems. After a cohort is extinct, we can check whether this cohort's budget sheet was in balance, and, if not, how much the cohort gained or lost. In this paper, the proposed indicator of intergenerational equity $\left(E^{g}\right)$ is zero in case of perfect equity. If it is negative, this indicates that the members of, for instance, cohort $g$ received less on average in pension benefits than they paid in contributions.

20 As for intra-generational equity (discussed in the next section), AIPSs are the only schemes that expressly keep it under control, through the $Q$ parameter of eq. (7). 
Finally, the contribution rate $c_{t}$ should ideally remain constant, so as not to affect unpredictably the cost of labour or the standard of living of the employed (net of their pension contributions).

A couple of preliminary considerations should be mentioned here. In all pension systems, ageing makes things worse, all other things being equal. In this simulation, because of low fertility, the age structure of the population gets considerably older at first, with the worst period coming 80-90 years after the start of the simulation. Since the average adult labour earning remains constant (by construction) and there are relatively few adults in the population, the average standard of living declines. This worsening of living conditions can either be spread over the entire population (the best case, in my view) or be concentrated on a smaller group. In this scenario, a constant contribution rate-which is apparently a good thing in itself-simply indicates that the standard of living of the employed (essentially, the adults) remains the same, and the burden of the bad situation falls entirely on the shoulders of the seniors. ${ }^{21}$

Another important preliminary point is that in all systems based on upward transfers (in which resources flow from the adults to the seniors) population increases or decreases are equivalent to capital gains or losses (Lee 1994). As the population declines in our scenario, there is an equivalent loss of capital. Therefore, there must be intergenerational inequity: at least some cohorts will get back less in pension benefits than they paid in contributions. The relevant question is not about the amount of the loss itself (which is basically the same in all four pension systems $^{22}$ ), but about its concentration: the worst possible case is when the loss falls entirely on a single cohort, while the best possible case is when this loss is spread equally across all of the cohorts under study. This can be measured by the variance of the generational losses: the lower the variance (i.e. the more equally spread these losses are), the better.

\subsection{Results}

The results of the simulation can be summarized in three figures. Figure 4 shows the evolution over time of what I think is the single most important indicator: the ratio between the average pension benefit and the average net adult's wage. Only $A I P S$, by construction, always preserves the original (socially preferred) value. $R S$ (risk sharing) is the second best option, but by focusing only on the labour earnings of the employed (whose labour productivity declines here) it fails to consider that there is a counterbalancing increase in the employment rate, and unjustifiably pays progressively lower pension benefits. Other solutions (DC or DB) are far worse.

21 The reverse happens when pension benefits remain constant (as in the DB scenario).

22 But with AIPSs child benefits are possible, which can substantially reduce this problem (not discussed here). 
Figure 4:

Cross-sectional relative welfare of seniors with respect to adults $\left(\pi_{t}\right)$

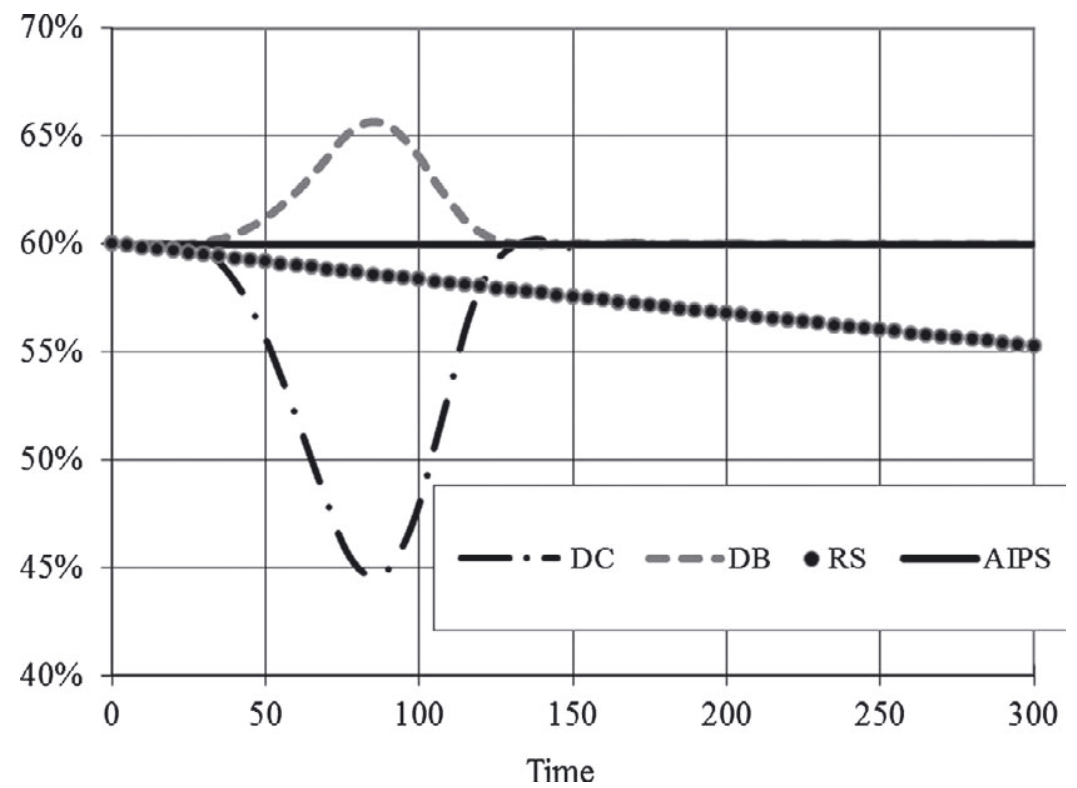

Note: DC: defined contribution; DB: defined benefit; RS: risk sharing; AIPS: almost ideal pension system. Source: Author's simulations.

My second indicator is intergenerational equity. In Figure 5 this indicator is relative to the average lifetime earnings of a cohort, and negative values indicate a loss. As expected, all of the proposed pension systems suffer a capital loss in this scenario (up to $3 \%-4 \%$ ) because of population reduction, but, as measured by the variance of the generational losses, the concentration of this loss is highest in the DB system (a few cohorts pay a high price), and lowest in the RS system. The AIPS is the second-best option, according to this indicator.

Finally, Figure 6 considers the payroll contribution rate $c_{t}$, which remains constant only in the DC system (by definition). This means that the employed are isolated from what happens to the standard of living of the population as a whole, which, however, has its drawbacks, as discussed above. In all of the other cases the contribution rate varies over time, but in the AIPS (and in the RS system) this change is smaller than in the DB system, because it is assumed that the deteriorating economic conditions must translate into lower standards of living for all of the population subgroups, and that this decline is proportionally the same for everybody, working-age adults and seniors alike. It should be noted that in the RS system as well, $c_{t}$ declines over time because pensions benefits are, in our scenario and with this mechanism, progressively smaller. 
Figure 5:

Intergenerational equity ${ }^{g} \boldsymbol{E}$ (net cohort gain or loss, relative to total pension contributions)

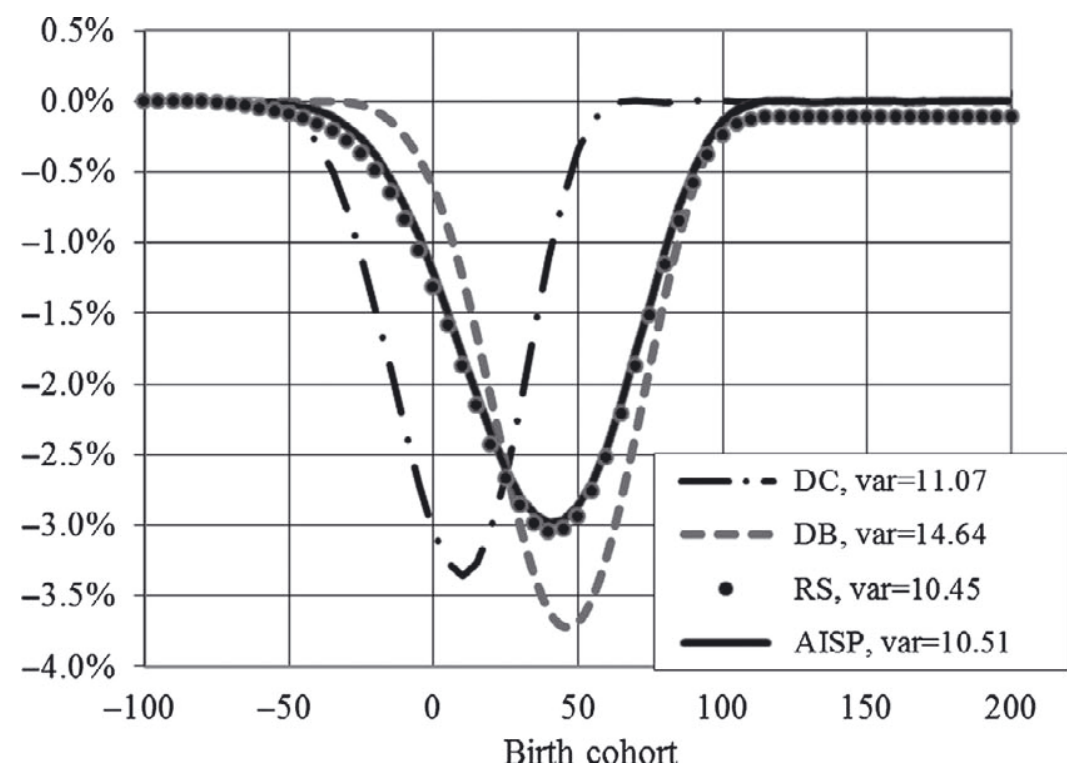

Note: DC: defined contribution; DB: defined benefit; RS: risk sharing; AIPS: almost ideal pension system; var: variance of the loss (a higher variance signals greater inequality in the distribution of the loss).

Source: Author's simulations.

Figure 6:

Payroll contribution rate $c_{t}$

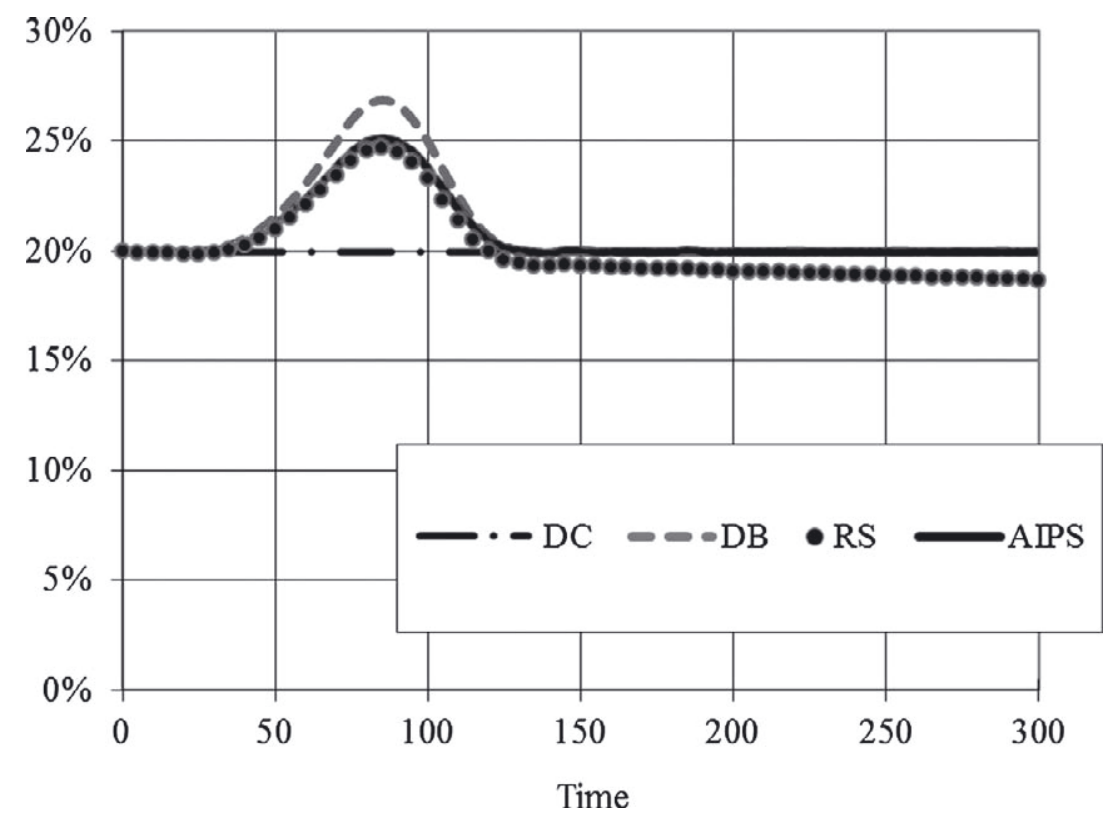

Note: DC: defined contribution; DB: defined benefit; RS: risk sharing; AIPS: almost ideal pension system. Source: Author's simulations. 
Table 1:

Demographic assumptions and policy variables for the simulation: two stationary subpopulations, blue and white collars, with different average lengths of life

\begin{tabular}{lcccc}
\hline & & Blue C. & White C. & All \\
\hline Life expectancy & $\mathrm{e}_{0}$ & 79.2 & 84.3 & 81.7 \\
Contribution rate & $c$ & $20 \%$ & $20 \%$ & $20 \%$ \\
First threshold age & $\alpha$ & 20 & 20 & 20 \\
Second threshold age & $\beta$ & 65 & 65 & 65 \\
Share of young people & $Y, Y^{*}$ & $25.1 \%$ & $23.6 \%$ & $24.4 \%$ \\
Share of seniors & $S, S^{*}$ & $20.2 \%$ & $24.2 \%$ & $22.2 \%$ \\
\hline
\end{tabular}

Source: Author's simulations.

\section{AIPSs and population heterogeneity}

All of the pension systems are based on average population survival, and therefore favour long-living population subgroups at the expense of others, because those who live longer benefit from pension payments for more years. It seems worthwhile to try to evaluate the extent of the intra-generational inequity caused by these demographic differences, and, if possible, to reduce it. In AIPSs this is feasible, within limits.

For the sake of clarity, I will consider only a very simple case, with no demographic or economic change over time. The introduction of dynamics would make the problem more difficult, but it would not add anything to the focal point of discussion here: the extent of intra-generational (between groups) unfairness implicit in a pension system with common rules but heterogeneous subpopulations, and the possible remedies.

Table 1 displays the essential information. A stationary population is made up of two equally numerous stationary subpopulations, blue and white collars, who are, by assumption, rigidly separated since birth, with no upward or downward social mobility. The average length of life is assumed to be shorter for blue than for white collars $\left({ }^{b} e_{0}=79.2,{ }^{w} e_{0}=84.3\right)$. The difference, 5.1 years, is larger than it is between the equivalent male subgroups in Finland (van Raalte et al. 2014), a developed country where heterogeneity in survival in particularly high (Mackenbach et al. 2003). However, in more specific population subgroups, the gaps can be even wider (Blanpain 2011).

In all of the scenarios the pension system is in equilibrium, the average length of life for the entire population is 81.7 years (including both blue and white collars), and $\alpha=20$ and $\beta=65$ are the conventional threshold ages that separate the young people $\left(Y=Y^{*}=24.4 \%\right)$ from the working-age adults $\left(A=A^{*}=54.4 \%\right)$, and the working-age adults from the seniors $\left(S=S^{*}=22.2 \%\right)$.

Table 2 (panels to be read clockwise) summarizes the main conclusions of our four scenarios. In scenario $A$ the average adult labour earnings are the same 
Table 2:

Economic and policy scenarios (A to D, clockwise) for the evaluation of the intra-generational equity of an AIPS arrangement with population heterogeneity: blue and white collars
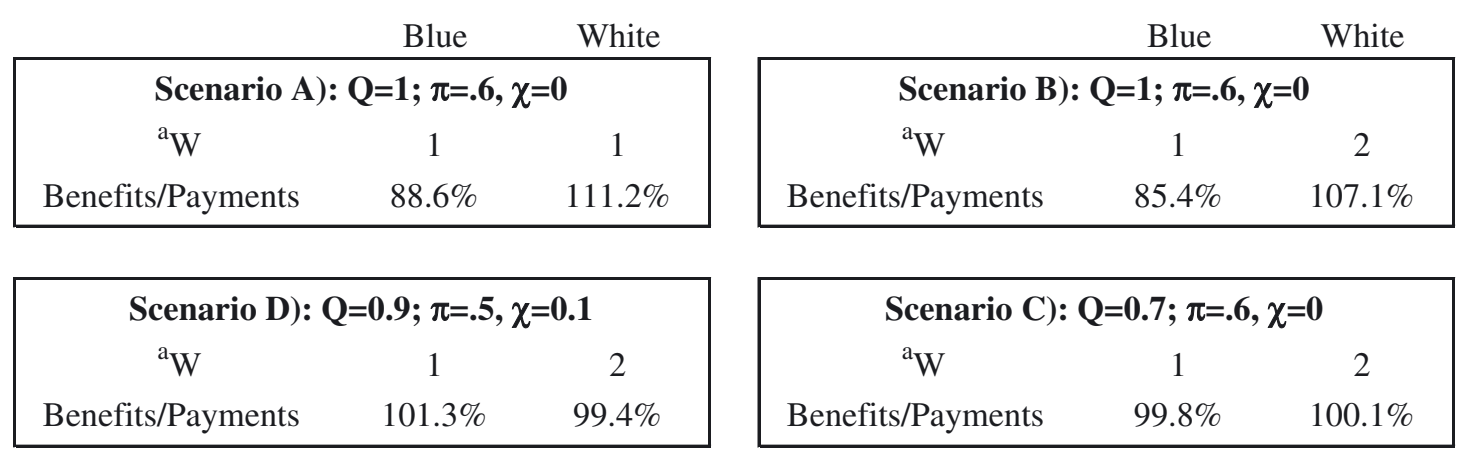

Source: Author's simulations.

in the two groups, blue and white collars, ${ }^{23} Q=1$ (perfect actuarial equity; no redistribution to the poor), $\chi=0$ (no child benefits) and $\pi=0.60$ (the average pension benefit is $60 \%$ of the average net earnings of an adult). In this case, as expected, blue collars, who die younger, lose money: they get back in benefits only about $89 \%$ of the amount they paid in contributions. The balance goes to white collars, who spend more years collecting a pension, and who receive about $11 \%$ more than they paid in.

In scenario $B$, white collars earn on average twice as much as blue collars, all else being equal. In absolute terms the transfer of resources is now larger than before (because, with $Q=1$, those who earn more and pay higher contributions also receive proportionally higher pension benefits). This explains why blue collars lose more than they did in scenario $A$ : their benefits correspond to only around $85 \%$ of their payments. The $14.6 \%$ blue collars lose goes to white collars, but it becomes a mere $+7.1 \%$ for the white collars, because the incomes (labour earnings and pensions) of the white collars are twice as high as those of the blue collars. In sum, these figures remind us of the risk of an involuntary, but substantial, transfer of resources from the poor to the rich in a pension system if no corrective action is taken to adjust for the different survival rates of the two groups.

A simple corrective measure would be to introduce some redistribution from the rich to the poor through the $Q$ parameter. In scenario $C$ this $Q$ parameter is set at $70 \%$, which means that the pension system mainly (70\%) uses actuarial equity, but also has a non-trivial Beveridgean (or redistributive) component $(1-Q=30 \%$ ).

23 In this table and in the following the average adult labour earnings of the reference category (blue collars and men) is normalized to one, while the others may earn the same (one), or twice as much (two; white collars), or half as much (0.5; women). Reminder: the average labour earnings of the adults ${ }^{a} W$ are the average earnings of the employed ${ }^{e} W$ multiplied by the employment rate $e(=E / A)$ (eq. (4)). 
This is enough to completely offset the advantage of the longer living group: both blue and white collars now get back in pension benefits around $100 \%$ of the amount they paid in contributions when they were employed.

With the inclusion of some child benefits (in scenario $\mathrm{D}, \chi=10 \%$ of the average net adult earning, and pension benefits are reduced to $\pi=50 \%$, so as to maintain the contribution rate at $c \approx 20 \%$ ), the explicit Beveridgean component $(1-Q)$ can be substantially mitigated. Already with $(1-Q)=10 \%$ life-time payments match lifetime benefits for both blue and white collars. This happens because child benefits are intrinsically Beveridgean: each child receives the same amount, which is relatively high for poor (blue collar) families and relatively low for rich (white collar) families.

In short, even with extreme assumptions (no social mobility and very marked differences in survival and earnings), introducing a mild degree of redistribution into the system can fully compensate the poor for the economic disadvantages they suffer because of their shorter lives (mainly as pensioners).

However, this does not solve all of the problems. Table 3 mirrors Table 2, but now I compare men and women. ${ }^{24}$ Men die younger, but they earn more (both their employment rate and their average labour earnings are higher): in Table 3 (scenarios $B, C$, and $D$ ), their average adult earnings are supposed to be twice as high. In this case, with $Q=1$, there is a substantial transfer of resources from men to women because women outlive men (scenarios $A$ and $B$ ). All attempts at introducing some Beveridgean component make this situation worse (scenarios $C$ and $D$ ), because in this case the rich (males) are also those who die younger. This transfer of resources from men to women is compatible with women receiving lower pension benefits: in scenario $B$, for instance, the average woman's yearly pension benefit is exactly half as large as the average man's because no redistribution is envisaged, and because women earn half as much in their adult years.

The prevalent opinion is that this transfer of resources from men to women is a just compensation for the obstacles women encounter in professional life: for example, they are discriminated against in the labour market and have more family obligations (Bonnet and Hourriez 2012). I disagree, but I would rather not discuss this topic here. I introduced it merely to show that AIPSs make it possible to keep the relevant variables under control, even if redressing biases is not always easy.

\section{Conclusions}

AIPSs are based on a few simple concepts. In economic terms, these systems reflect in practice the basic observation made by (Barr 2002) that pension 'rights' are simply a claim on current production. The current production is the salary mass $E G$ (the employed multiplied by their gross average labour revenue), which

24 The average durations of life for men and women cited in Table 3 are those observed in Italy in 2010. 
Table 3:

Economic and policy scenarios (A to D, clockwise) for the evaluation of the intra-generational equity of an AIPS arrangement with population heterogeneity: men and women
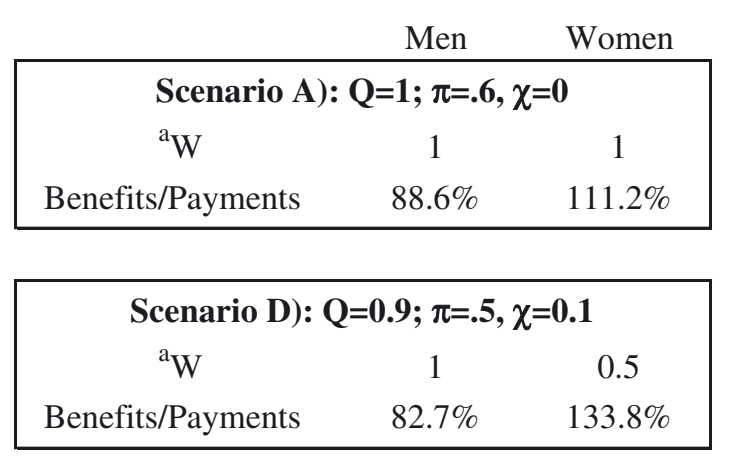
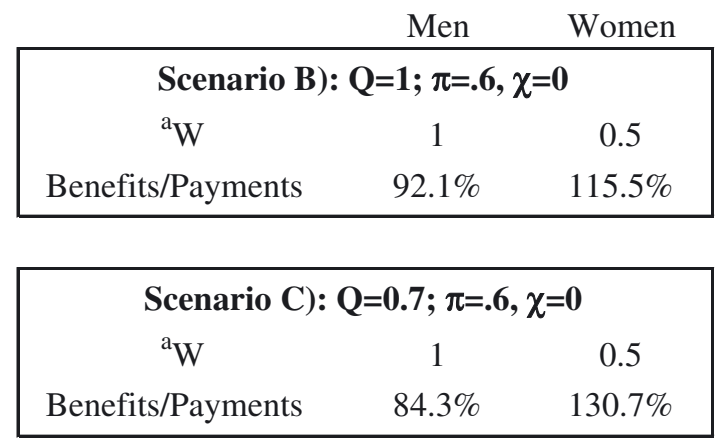

Source: Author's simulations.

AIPSs reinterpret as $A^{a} G$, where ${ }^{a} G(=e G)$ encompasses the only two economic variables which matter in this field: how many are employed $E$, given the adult population $A(e=E / A)$, and how productive they are $(G)$. The challenge is to fine-tune these claims so that pension benefits remain 'fair' (high enough, but economically sustainable) at all times. What is 'fair' is not for demographers or economists to decide: that is determined by policy makers, who may of course base their decisions in part on economic and welfare analyses on choice optimization (not discussed here). This principle also applies in determining the appropriate allocation across the life span of young, adult, and senior ages; and on the optimal degree of redistribution that should be embedded in the system.

In terms of demography, several options can be considered, but keeping the shares of young $Y^{*}$, adults $A^{*}$, and seniors $S^{*}$ constant in the reference population appears to be the most obvious and most sensible choice. As life spans grow longer and people maintain their health at older ages (a trend which is not discussed here), the threshold ages must shift upwards in order to preserve the socially preferred balance between the average time spent as a non-producer (child or senior) and as a working adult. Regardless of their cause (survival, fertility, or migration), the changes in the current age structure translate into a time-varying contribution rate which ensures that the financial equilibrium of the system is always preserved.

AIPSs are designed to remain viable forever even without modifications. Thus, changes are possible, but are never necessary. While the implementation of such a system may seem to be too ambitious, AIPSs appear to be the only effective way for future generations to protect themselves from the rapacious demands of the present generation. In the long run we may well all be dead, as Keynes (and others) prophesized, but our children will not; I therefore submit that a properly designed pension system should form part of our legacy. 


\section{References}

Barr, N. 2002. Reforming pensions: Myths, truths, and policy choices. International Social Security Review 55(2): 3-36. http://eprints.lse.ac.uk/286/1/Barr_2002_ISSR020108.pdf.

Belloni, M., R. Alessie, A. Kalwij and C. Marinacci 2013. Lifetime income and old age mortality risk in Italy over two decades. Demographic Research 29(45): 1261-1298.

Blanpain, N. 2011. L'espérance de vie s'accroît, les inégalités sociales face à la mort demeurent. Insee première, 1372, http://www.insee.fr/fr/ffc/ipweb/ip1372/ip1372.pdf.

Bonnet, C., J.-M. Hourriez 2012. Egalité des hommes et femmes à la retraite: quels rôles pour les droits familiaux et conjugaux? Population-F 67(1): 133-158.

Börsch-Supan, A. H. 2008. The impact of global aging on labor, product, and capital markets. Population and Development Review 34 (Population aging, human capital accumulation, and productivity growth): 52-77.

Cigno, A. and M. Werding 2007. Children and Pensions. Cambridge/London: MIT Press.

Demeny, P. 1986. Pronatalist policies in low-fertility countries: Patterns, performance and prospects. Population and Development Review 12 (Supplement): 335-358.

Demeny, P. 1987. Re-thinking fertility behaviour and economic security in old age: a pronatalist reform. Population and Development Review 13(1): 128-132.

De Santis, G. 2003. The demography of an equitable and stable intergenerational transfer system. Population-E 58(6): 587-622.

De Santis, G. 2011. Can immigration solve the ageing problem in Italy? Not really.... Genus 67(3): 37-64.

De Santis, G. 2012. The demographic phases and the Almost Ideal Pension System (AIPS). In The Family, the Market or the State? Intergenerational Support under Pressure in Ageing Societies, ed. De Santis, Dordrecht/Heidelberg/New York/ London: Springer.

Gonnot, J.-P., N. Keilman, Prinz C. 1995. Social security, household and family dynamics in ageing societies, Dodrecht/Boston/London: Kluwer Academic Publishers.

Gruber, J. and D. A. Wise, eds. 1999. Social Security and Retirement Around the World. National Bureau of Economic Research: University of Chicago Press.

Guillot M., and H. S. Kim 2011. On the correspondence between CAL and lagged cohort life expectancy. Demographic Research 22(25): 611-632.

Knell M. 2013. Increasing life expectancy and pay-as-you-go pension systems, mimeo, http://www.euro.centre.org/data/1367257051_49464.pdf.

Kohli, M. and C. Arza 2011. The political economy of pension reform in Europe. In Handbook of Aging and the Social Sciences, 7th Edition, ed. R. H. Binstock and L. K. George. Amsterdam: Academic Press.

Kruse, A. 2010. A stable pension system: The eighth wonder. In Population Ageing. A Threat to the Welfare State? The Case of Sweden, ed. T. Bengtsson, 47-64. Heidelberg: Springer.

Lee, R. D., 1994. Fertility, mortality and intergenerational transfers. Comparisons across steady states. In The family, the market and the state in ageing societies, ed. J. Ermish and N. Ogawa, 135-157. Oxford: Clarendon Press. 
Mackenbach, J. P., V. Bos, O. Andersen, M. Cardano, G. Costa, S. Harding, A. Reid, Ö. Hemström, T. Valkonen and A. E. Kunst 2003. Widening socioeconomic inequalities in mortality in six Western European countries. International Journal of Epidemiology 32: 830-837. doi:10.1093/ije/dyg209.

Musgrave, R. A. 1981. A reappraisal of financing social security, in Social security financing, ed. F. Skidmore, 89-127. Cambridge (Mass.): MIT Press.

OECD 2013. Pensions at a Glance 2013: OECD and G20 Indicators, OECD Publishing. doi:10.1787/pension_glance-2013-en.

Oeppen, J. and J. W. Vaupel 2002. Broken limits to life expectancy. Science 296: 1029-1031.

Orszag P. R. and J. E. Stiglitz 2001. Rethinking pension reform: Ten myths about social security systems, in New Ideas About Old Age Security. Toward Sustainable Pension Systems in the 21 st Century, ed. R. Holzmann and J. E. Stiglitz, 17-62. Washington DC: The World Bank.

Preston, S. H. and A. Stokes 2012. Sources of population ageing in more and less developed countries. Population and Development Review 38(2): 221-236.

Sánchez-Romero, M., J. Sambt and A. Prskawetz 2013. Quantifying the role of alternative pension reforms on the Austrian economy. Labour Economics 22(1): 94-114.

Sanderson, W. C. and S. Scherbov 2013. The characteristics approach to the measurement of population aging. Population and Development Review 39(4): 673-685.

Settergren, O. and Mikula, B. D. 2006. The rate of return of pay-as-you-go pension systems: A more exact consumption-loan model of interest, in Pension Reform: Issues and Prospects for Non-Financial Defined Contribution (NDC) Schemes, ed. R. Holzmann and E. Palmer, 117-142, Washington, DC: The World Bank.

Shkolnikov, V. M., D. A. Jdanov, E. M. Andreev, and J. Vaupel 2011. Steep increase in best-practise cohort life expectancy. Population and Development Review 37(3): 419-434.

UN 1997. Glossary of Environment Statistics, UN: New York. http://unstats.un.org/unsd/ publication/SeriesF/SeriesF_67E.pdf.

van Raalte, A. A., P. Martikainen and M. Myrskylä 2014. Lifespan variation by occupational class: Compression or stagnation over time? Demography 51(1): 73-95. 